\title{
Scaphoid-Capitate Joint
}

National Cancer Institute

\section{Source}

National Cancer Institute. Scaphoid-Capitate Joint. NCI Thesaurus. Code C127676.

A condyloid synovial joint within the wrist connecting the scaphoid bone to the capitate bone. 